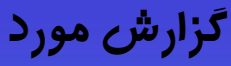

\section{در رفتكى دو طرفه قدامى مفصل شانه بدنبال مصرف ترامادول}

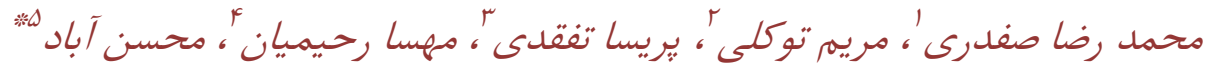
متخصص ارتويدى، بيمارستان امام على(ع)، دانشعاه علوم يزشكى خراسان شمالى، بجنورد

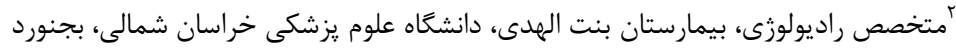

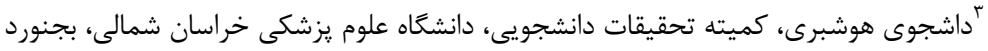

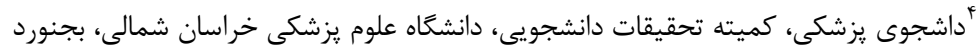

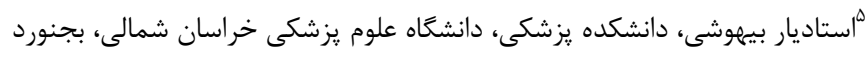

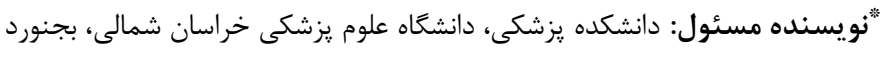
: mohsen.abad@yahoo.com : يست الكترونيك

جكبد

مصرف ترامادول مى تواند منجر به تشنج شله و باعث درفتتى دو طرفه قدامى مفصل شانه شود.

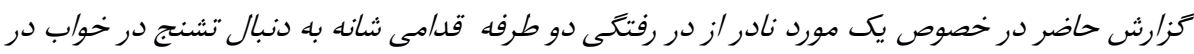

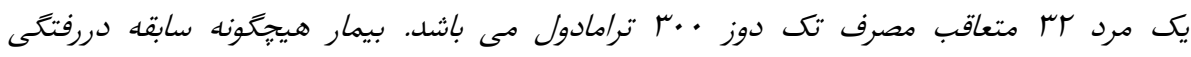

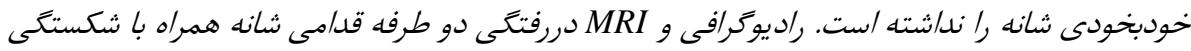

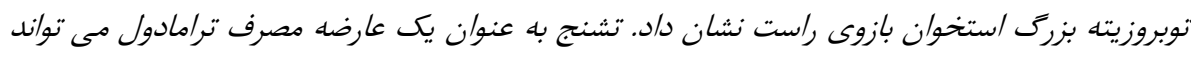

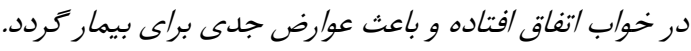
وازه هاى كليدى: ترامادول، دررفتكى شانه، تشنج

وصول: يذيرش: و 
هيج نكته غير طبيعى نداشته است. در مراجعه مجدد به

بيمارستان مجددا تشخيص هيسترى به عنوان تشخيص

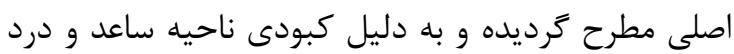

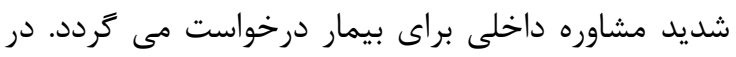

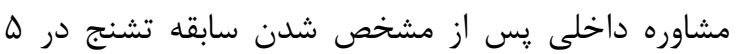

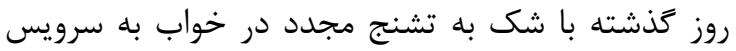

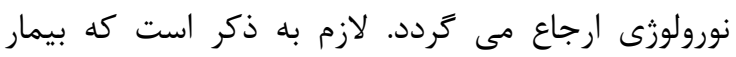

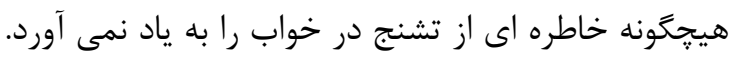

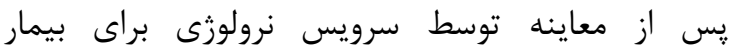
درخواست MRI براى هر دو مفصل داده شده و به بيمار

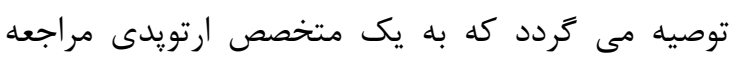

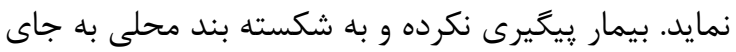

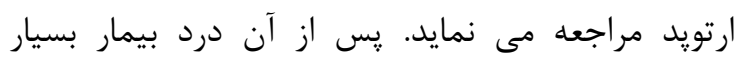

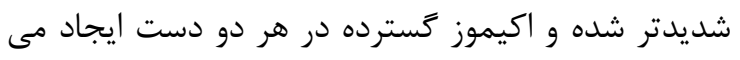

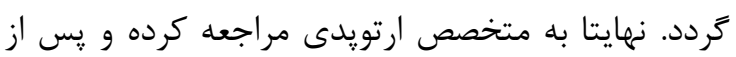
رويت MRI و نيز درخواست كرافى دو طرفه مفصل شانه

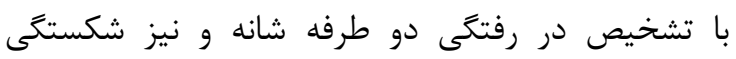

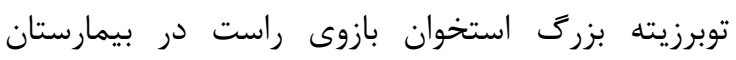
بسترى مى گردد. كرافى انجام شده بيمار در شانه جٍٍ در

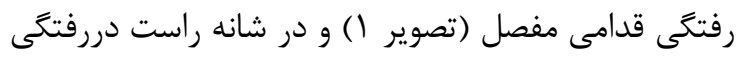

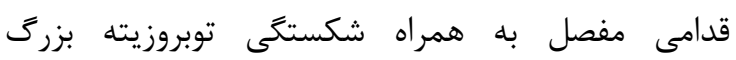

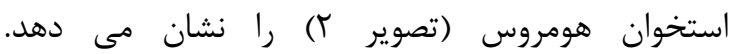
راديولوزيست در تزارش MRI موارد فوق را مورد تاييد

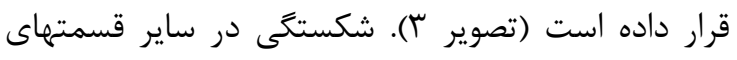

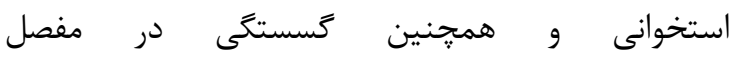
اكروميوكلاويكولار رويت نكرديد. روز بعد بيمار به اتاق عمل منتقل شده و يس از بيهوشى، مفاصل شانه جا

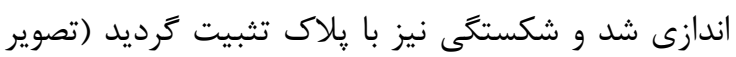

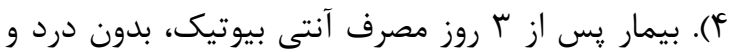

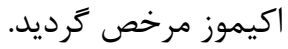

مصرف ترامادول در محدوده درمانى نيز ممكن است باعث تشنج گردد ، اين تشنج ممكن است در خواب اتفاق افتاده و حتى باعث دررفتگى قدامى دو طرفه شانه كردد. در رفتخى قدامى شانه يكى از شايعترين مشكلاتى داست كد

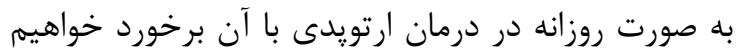
كرد كه بايد به طور مناسب درمان كردد. در عين حال بران بران
دررفتگى مفصل شانه شايعترين دررفتگى است كه در

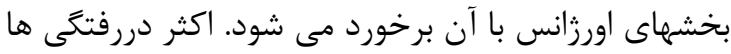

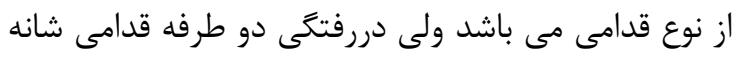
نادر است و در صورت رخداد بيشتر از نوع خلفى مى بـ باشد.

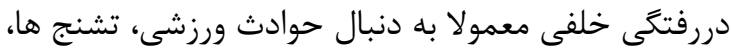

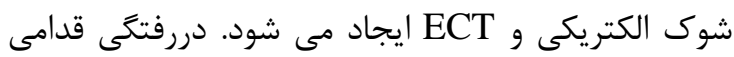

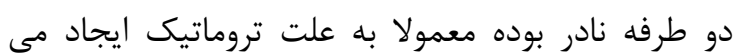

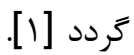
ترامادول يك مخدر ضد درد است كه در درمان دردهاى

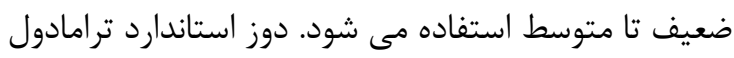

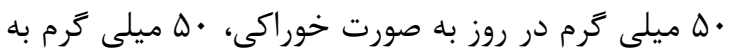
صورت وريدى و يا .ا ميلى كرم از راه ركتال مى بـ باشد.

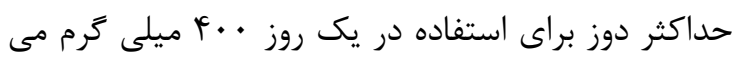

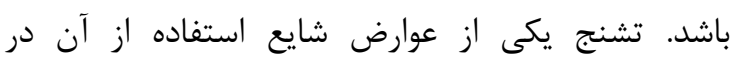
دوزهاى درمانى، سوء مصرف و يا مصرف بيش از حد مى بـ إنى باشد [r.r. معرفى بيمار: ززارش اين مورد به اين دليل صورت كرفته است كه بيمار بعد از مصرف ترامادول در خواب دجار

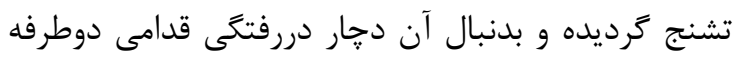

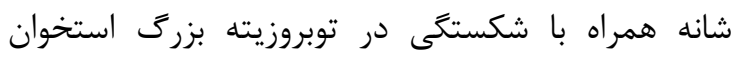

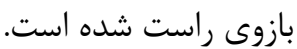
كزارش مورد: بيمار مردى Tr ساله است كه با شكايت عدم توانايى در حركت دو دست به بيمارستان مراجعه مي مردي

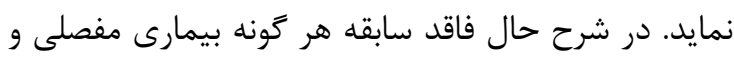

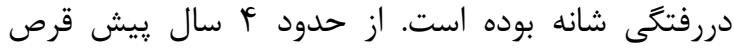
ترامادول را به ميزان روزانه

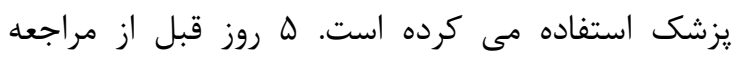

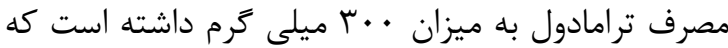
متعاقب آن دجار تشنج گرديده است ولى مراجعه به به يزشك و يا مراكز درمانى نداشته است. شب قبل از مراد مراجعه

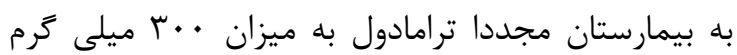
استفاده كرده است. صبح يس از بيدار شدن از بداد خواب

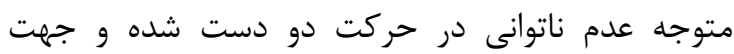
درمان به بيمارستان مراجعه مى نمايد. در اولين مراجعه با درات تشخيص هيسترى يس از يك شب بسترى در اورزانس و

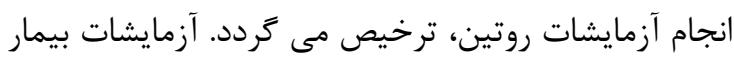




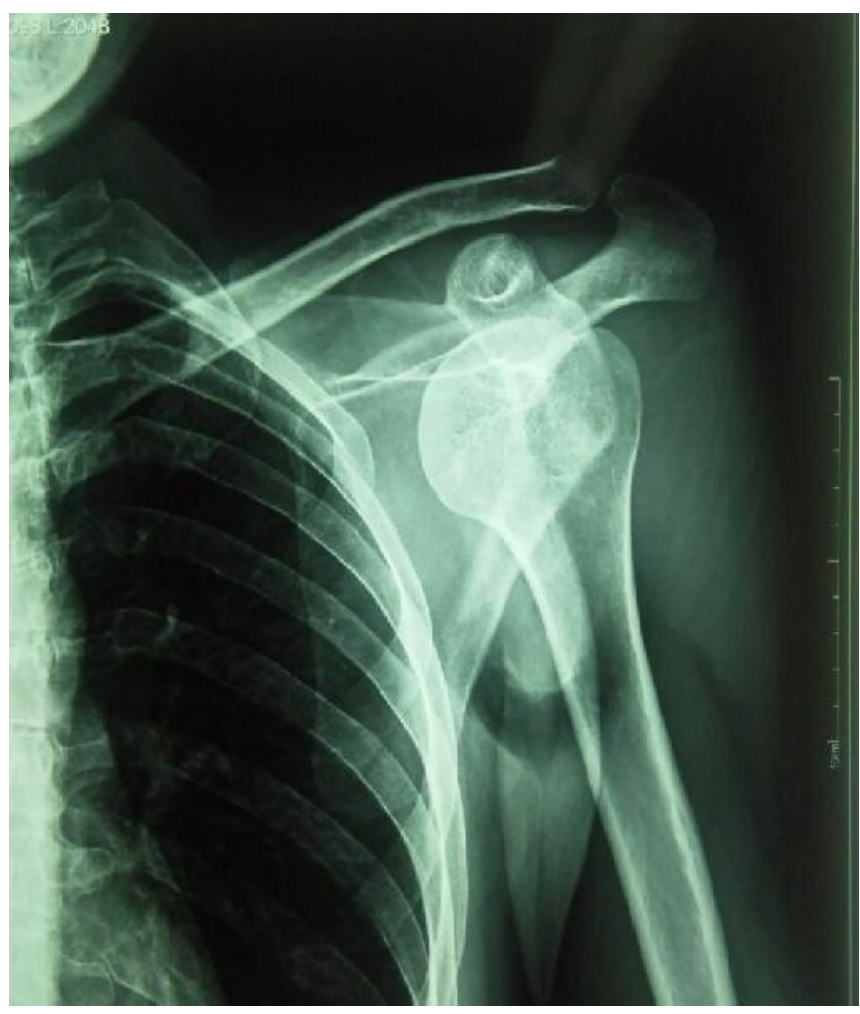

تصوير ا: راديوكرافى مفصل شانه جֶٍ بيمار

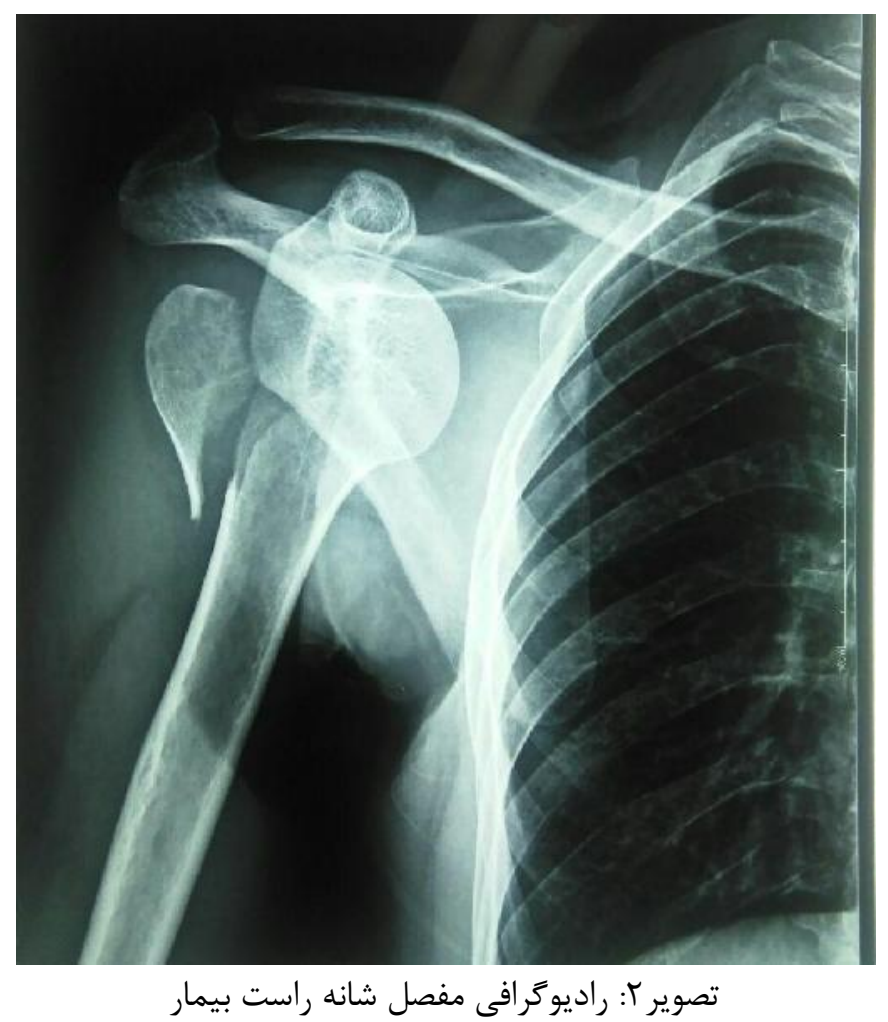



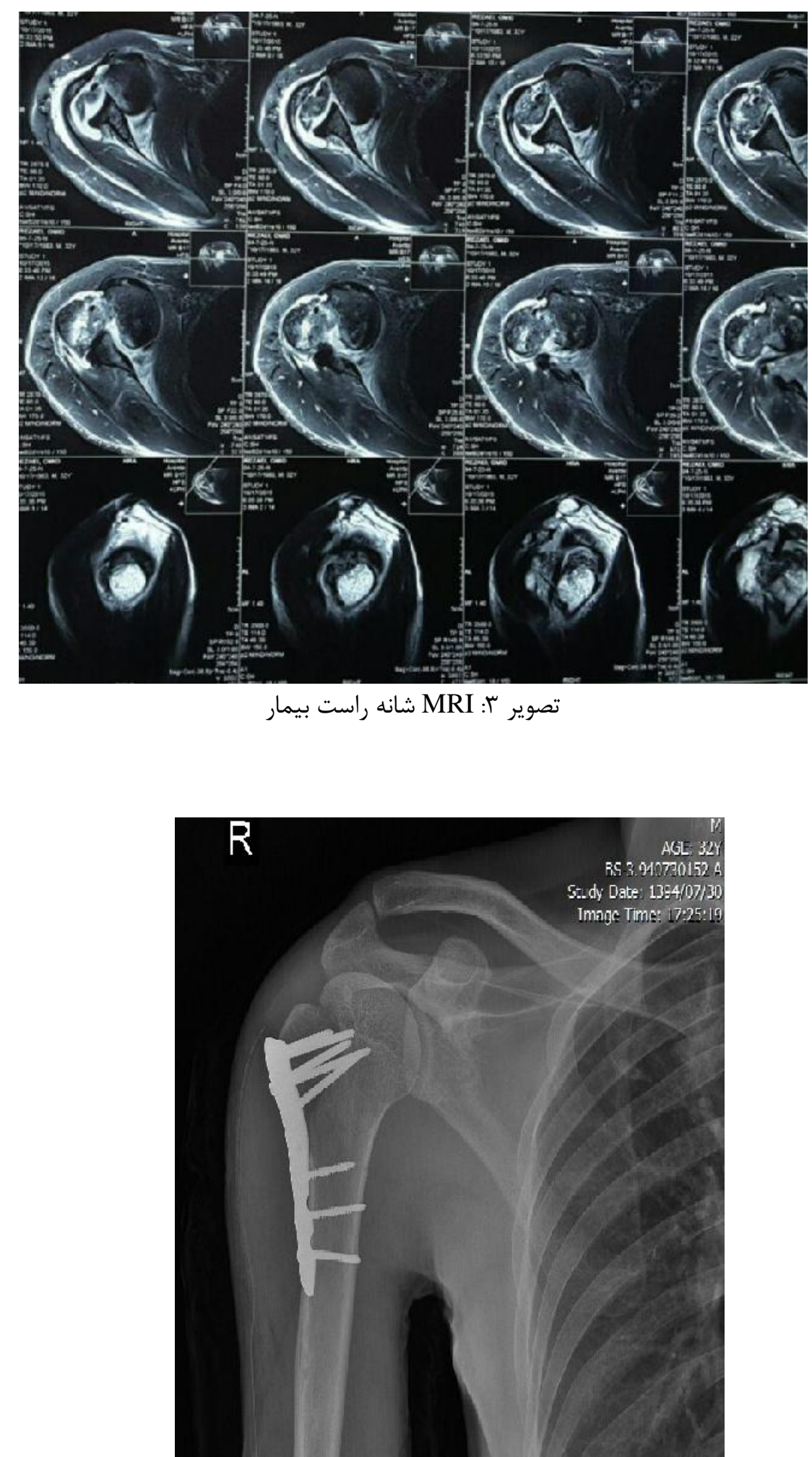

تصوير fا: تثبيت شكستگى توبريزيته بزرى استخوان بازوى راست با پِلاك 
است. آنجه را كه بايد در بيمارانى كه به دنبال مصرف ترامادول، دجار تشنج شده اند در نظر داشت صدمات

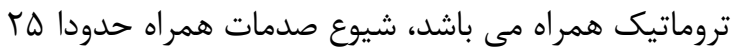
درصد بوده و شايعترين محل، تروماى صورت مى بـ باشد.

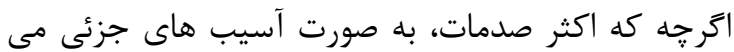
باشد ولى آسيبهاى جدى تر را نبايد از نظر دور داشت. جرا كه شكستكى جمجمه و خونريزى ساب آراكنوئيد نيز در اين موارد كزارش شده است [^]ـ.

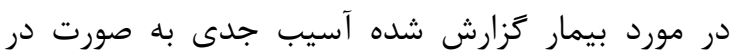

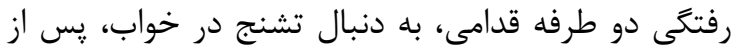

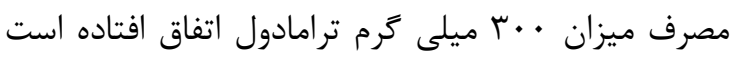

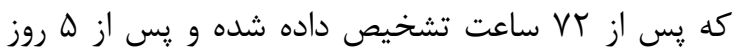

$$
\text { تحت درمان قرار كرفته است. }
$$

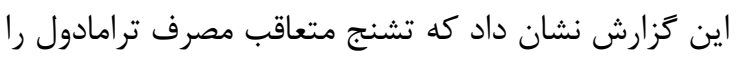
به عنوان يك عارضه مهم در نظر داشت و نيز بايد توجه كرد كه ممكن است اين تشنج در خواب اتفاق افتاده و خود بيمار هيج شرح حالى در اين مورد به خاطر نداشته

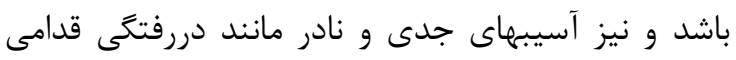

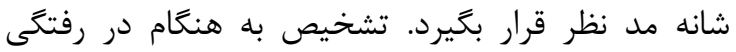
بسيار مهمم مى باشد جرا كه يك اورزانس ارتويدى بوده و

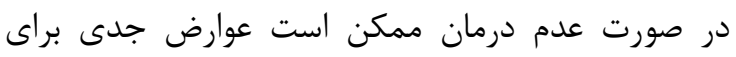
بيمار ايجاد نمايد. تجويز ترامادول بايد با احتياط صورت گرفته و در صورت

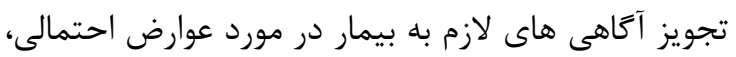
به خصوص تشنج، داده شود.
دررفتتى دو طرفه قدامى شانه، بسيار نادر مى باشد و در صورت عدم معاينه صحيح بيمار مى تواند به راحتى مورد غفلت قرار كيرد. شكل خلفى در رفتنى، شايع تر است و و

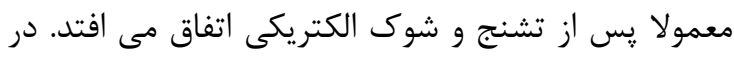
حالى كه دررفتگى قدامى شانه معمولا به دليل تروما به

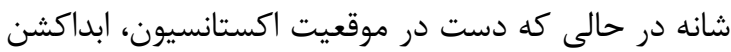

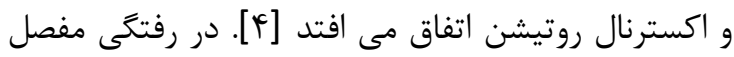

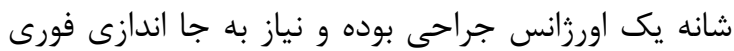

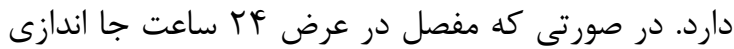

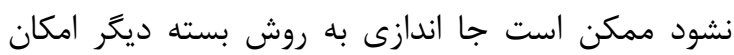

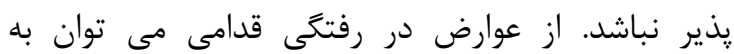

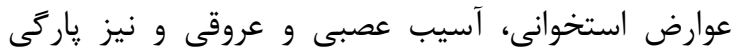
روتاتور كاف اشاره كرد. صدمات عروقى معمولا به صورت آسيب شريان آتزيلارى كاف

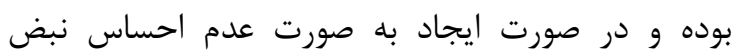
ديستال تظاهر ييدا مى كند. آسيب عصبى در در فتلى آنى

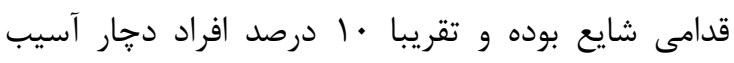
عصب آكزيلارى مى تردند [هايع]. ترامادول يك ضد درد صناعى است كه براى درمان دردهاى خفيف تا متوسط استفاده مى شود. مصرف ترامادول در محدوده دوز درمانى و توكسيك مى تونى تواند

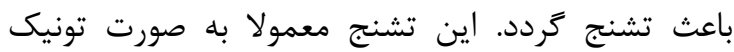

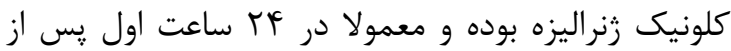

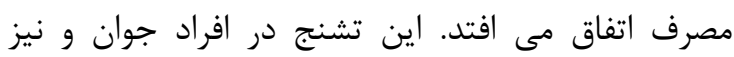
افراديكه سابقه مصرف طولانى دارند و نيز كسانيكه مصرف همزمان الكل دارند، بيشتر اتفاق مى افتد [ع]. البته بايد در نظر داشت كه شيوع تشنج در صورت استفاده در

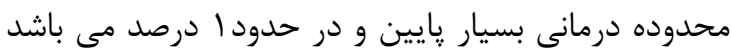

بنا به گزارشات، استفاده از ترامادول در ايران و جهان رو به

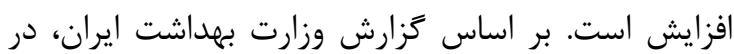

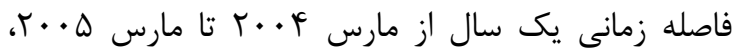

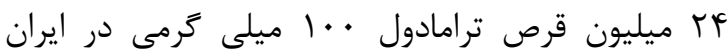

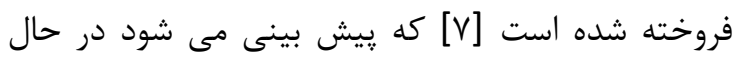
حاضر مصرف آن افزايش جشمخيرى داشته باشد. در يك مطالعه نشان داده شد كه حداقل دوز ترامادول كه

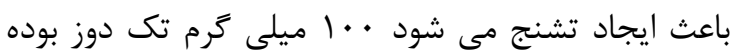


محمد رضا صفلرى و همكاران

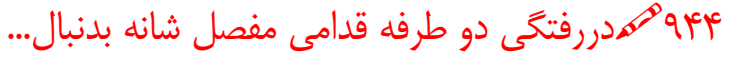

\section{References}

1.Snjay Meena,PramodSaini,VivekSingh,RamakantKumar and VivekTrikha-bilateral anterior shoulder dislocation-a case report-J Nat SciBiol Med. 2013 Jul-Dec; 4(2): 499-501

2.Shadnia s1,Brent j,mousavi-fatemik,hafezip,soltaninejad k-recurrent seizure in tramadol intoxication: implications fore therapy based on 100 patients-Basic ClinPharmacolToxicol 2012 Aug;111(2):133-6. doi:10.1111/j.1742-7843.2012.00874.x. Epub 2012 Mar 22[Persian]

3.Taghaddosinejad F1, Mehrpour O, Afshari R, Seghatoleslami A, Abdollahi M, Dart RC-Recurrent seizures in tramadol intoxication: implications for therapy based on 100 patients-J Med Toxicol 2011 Sep;7(3):183-8. doi: 10.1007/s13181-011-0168-0[Persian]

4. Yuk Chuen Siu1 and Tun Hing Lui1- Bilateral Anterior Shoulder Dislocation- Published online 2014 Nov 18. doi: 10.5812/atr.18178- Arch Trauma Res. 2014 Nov; 3(4): e18178

5. Steven Cutts, Mark Prempeh, and Steven Drew- Anterior Shoulder Dislocation- doi: 10.1308/003588409X359123- Ann R Coll Surg Engl. 2009 Jan; 91(1): 2-7

6. Naresh Nebhinani, Shubh M, Singh,1 and Gourav Gupta1- A patient with Tramadol dependence and predictable provoked epileptic seizures- doi: 10.4103/0019-5545.117153- Indian J Psychiatry 2013 Jul-Sep; 55(3): 293-294.

7. Morteza Nakhaei Amroodi,Gholamreza Reza Shafiee and Tahmineh Mokhtari: Prevalence of the Shoulder Dislocation Due to Tramadol-Induced Seizure: January 21, 2015[Persian]

8.Farajidana H, Hassanian-Moghaddam H,Zamani N,Sanaei-Zade H-Tramadol-induced seizure and truma-Eur Rev Med pharmacol Sci.2012 Mar:16 Suppl 1:34-7[Persian] 


\title{
Bilateral anterior shoulder dislocation following trramadol use
}

\author{
Safdari $M R^{1}$, Tavakoli $M^{2}$, tafaghodi $P^{3}$, Rahimian $M^{4}$, Abad $M^{5} *$
}

1MD, Imam Reza Hospital, North Khorasan University of Medical Sciences, Bojnurd, Iran 2 MD, Bentol hoda Hospital, North Khorasan University of Medical Sciences, Bojnurd, Iran 3Medical Student, Student Research Committee, North Khorasan University of Medical Sciences, Bojnurd, Iran

4 Student Research Committee, North Khorasan University of Medical Sciences, Bojnurd, Iran 5Assistant Professor, Medical School, , North Khorasan University of Medical Sciences , Bojnurd, Iran

*Corresponding Author: Medical School, , North Khorasan University of Medical Science s, Bojnurd, Iran

Email: mohsen.abad@yahoo.com

\section{Abstract}

Seizure resulted from tramadol can cause bilateral joint dislocation. This study is a rare case report that represents fracture and dislocation of right shoulder due to seizure in a 32years old man that had consumed a 300mg single dose of tramadol. He did not have any history of previous seizure or spontaneous dislocation of the shoulder. The right shoulder radiography and MRI demonstrated dislocation of the head of humerus with fracture of its greater tuberosity. Seizure as a side effects of therapeutic dose of tramadol, can occur during sleep, resulting to serious complications

Keywords: Tramadol, shoulder dislocation, seizure 